\title{
PNL2000 - Método Prático de Dimensionamento Econômico de Redes Malhadas de Abastecimento de Água
}

\author{
Heber Pimentel Gomes \\ Universidade Federal da Paraíba - Departamentos de Tecnologia da Construção Civil - Campus I João Pessoa \\ Av. Oceano Atlântico, 198 - CEP 58310-000 Cabedelo, PB - heberp@uol.com.br
}

Klebber Teodomiro M. Formiga

ATECEL/UFPB - Caixa Postal 505

58100-970 Campina Grande, PB - klebberformiga@uol.com.br

Recebido: 05/11/00 - revisão: 10/05/01 - aceito: 05/08/01

\section{RESUMO}

Este trabalho apresenta um método de dimensionamento econômico de redes malhadas de abastecimento de água, a partir de técnicas de otimização econômica. O método denominado aqui de PNL2000, tem como objetivo encontrar os diâmetros das tubulações dos trechos da rede e a cota piezométrica de bombeamento, de modo que a soma dos custos de investimento e de operação do sistema de abastecimento de água seja a menor possível. A metodologia empregada está baseada no modelo matemático da programação não linear.

A formulação do método PNL2000 e a obtenção dos resultados do dimensionamento, se processam com a utilização da ferramenta Solver da planilha Excel da Microsoft. A aplicação do método foi comprovada mediante o dimensionamento de uma rede malhada de um setor de um sistema urbano de abastecimento de água. Os resultados do dimensionamento ótimo, demonstraram que todas as restrições hidráulicas do sistema de abastecimento foram atendidas.

Palavras-chave: PNL2000; redes malhadas.

\section{INTRODUÇÃO}

Os sistemas de abastecimento de água compreendem o conjunto de obras e equipamentos destinados a suprir as necessidades de consumos doméstico, público e industrial de uma comunidade. Esses sistemas devem fornecer água, em qualidade e quantidade, indistintamente às populações com o menor dispêndio possível.

Os sistemas de abastecimento de água podem ser divididos em cinco partes distintas: captação, adução, tratamento, reservatório de distribuição e rede de distribuição. As redes de distribuição são os componentes responsáveis por levar a água ao usuário final nos sistemas de abastecimento de água, de comunidades urbanas e rurais. Quanto à disposição dos tubos, essas redes podem ser classificadas em ramificadas, malhadas ou mistas.

As redes ramificadas se caracterizam por apresentarem um único sentido para o escoamento e suas tubulações são distribuídas em forma de ramos. A principal vantagem desse tipo de rede é que o seu custo de implantação é menor do que o de uma rede malhada de mesmo porte (Gouter et al., 1986). No entanto, as redes ramificadas apresentam inconvenientes na manutenção, visto que para se fazer um reparo em um determinado trecho, todo o ramal a jusante ficará sem água. Dessa forma, o emprego das redes ramificadas tem sido descartado em locais onde o abastecimento de água é imprescindível, como nos centros urbanos de médio e grande porte.

As redes malhadas apresentam os seus trechos interligados em forma de anéis, ou malhas, de forma que os fluxos têm sentidos e valores variáveis, fazendo com que o dimensionamento das tubulações se torne mais complexo, em comparação aos efetuados para redes ramificadas.

Atualmente, as técnicas mais utilizadas no dimensionamento da grande maioria das redes implantadas no Brasil são baseadas em métodos de tentativa e erro. Esses métodos fazem tão somente o balanceamento hidráulico do sistema, ficando a parte relativa aos custos de implantação a critério da experiência do projetista. Todavia, nos últimos anos, o crescente avanço da informática tornou 
possível o emprego de técnicas, desenvolvidas nas décadas de 60 e 70, que exigiam grande quantidade de cálculos, e que eram impossíveis de serem executados sem o auxílio de computadores avançados. Com o avanço da microinformática, em termos de hardware e de software, tem sido possível o emprego de técnicas de pesquisa operacional na resolução de problemas de dimensionamento de redes, baseados em critérios de otimização econômica.

As técnicas de otimização econômica começaram a ser aplicadas, para o cálculo de redes, no final dos anos 60. Karmeli et al. (1968) utilizaram a programação linear para encontrar o menor custo de redes ramificadas. Alperovitz e Shamir (1977) propuseram a utilização dessa técnica na minimização dos custos em redes malhadas. Gessler e Walsky (1985) desenvolveram o método WADISO, baseado na enumeração exaustiva das possíveis soluções. A metodologia GRANADOS, baseada em princípios de programação dinâmica (Granados, 1986), foi aplicada por Leal e Gomes (1997) na otimização das redes malhadas. Além dessas técnicas, outra que tem tido destaque é o Algoritmo Genético, aplicado na resolução de diversos problemas relacionados à otimização dos custos de implantação e também de operação em redes malhadas (Savic e Walters, 1997).

A metodologia utilizada no presente trabalho foi desenvolvida por Formiga (1999), sob a orientação do primeiro autor deste trabalho e é apresentada a seguir.

\section{METODOLOGIA}

A metodologia do PNL2000, que utiliza o modelo matemático da programação não linear, para o dimensionamento econômico de redes malhadas, se divide em duas etapas. Na primeira etapa, faz-se um pré-dimensionamento do sistema, no qual os diâmetros e as vazões dos trechos, e a cota piezométrica de cabeceira, são variáveis a serem determinadas no processo de otimização. Em seguida, com os resultados obtidos no prédimensionamento, executa-se uma segunda etapa, na qual se realiza o ajuste da solução inicialmente obtida. Nesta segunda etapa, o diâmetro contínuo calculado inicialmente para um determinado trecho, é desdobrado em dois diâmetros comerciais, um imediatamente superior e outro imediatamente inferior, considerando como incógnitas (variáveis de decisão) os comprimentos de seus sub-trechos, pertencentes ao trecho considerado. Além dos diâmetros e dos comprimentos dos tubos, as vazões nos trechos também são consideradas como variáveis a serem otimizadas, tanto na primeira como na segunda etapa do método.

Para realizar a otimização, o PNL2000 utiliza o método do Gradiente Reduzido Generalizado (GRG2), que é um algoritmo de programação não linear, desenvolvido por Lasdon et al. (1984). O modelo da programação não linear, a partir do GRG2, pode ser formulado e processado através da ferramenta Solver da planilha eletrônica Excel da Microsoft.

O dimensionamento das tubulações de redes malhadas pode ser efetuado considerando duas situações. Na primeira, a cota de cabeceira é tida como conhecida, sendo portanto uma constante do problema. No segundo caso, a cota piezométrica de cabeceira - que é a soma da cota do terreno com a altura manométrica - é considerada como variável a ser otimizada pelo dimensionamento. Assim, procura-se minimizar a soma dos custos de instalação tubos, peças, etc. - e de operação - que é representado pelo custo da energia de bombeamento. A relação antagônica desses dois custos é mostrada na Figura 1 (Gomes, 1999).

Os gastos com a implantação da rede, representados neste caso pelas tubulações e instalação, são denominados gastos fixos, ou de investimento, enquanto que os gastos com a operação (gastos energéticos) são variáveis e incidem ao longo da vida útil do sistema. Como esses gastos incidem em tempos diferentes, faz-se necessário converter, financeiramente, os gastos fixos em variáveis ou os gastos variáveis em fixos. Essa última alternativa foi a forma adotada no presente trabalho. Para tanto, faz-se necessário atualizar o custo de operação (energético), mediante a introdução na função objetivo, de um coeficiente que transforme os custos anuais em custos atualizados (Gomes, 1999).

\section{SOLUÇÃO INICIAL (PRIMEIRA ETAPA)}

\section{Função objetivo}

A equação que representa o custo total do sistema de abastecimento, que compreende o custo de implantação da rede mais o custo de operação da estação de bombeamento, pode ser expressa por:

$$
\mathrm{C}\left(\mathrm{D}_{\mathrm{i}}, \mathrm{Q}_{\mathrm{i}}, \mathrm{H}\right)=\sum_{\mathrm{i}=1}^{\mathrm{m}} \mathrm{L}_{\mathrm{i}} \mathrm{P}\left(\mathrm{D}_{\mathrm{i}}\right)+\mathrm{C}_{\mathrm{h}} \mathrm{H} \text { Fa }
$$


onde $\mathrm{C}\left(\mathrm{D}_{\mathrm{i}}, \mathrm{Q}_{\mathrm{i}}, \mathrm{H}\right)$ é o custo do sistema de abastecimento, em função dos diâmetros dos trechos $\mathrm{D}_{\mathrm{i}}$, das vazões requeridas nos nós da rede $Q_{i}$ e da altura de bombeamento $\mathrm{H}_{\text {; }} \mathrm{L}_{\mathrm{i}}$ é o comprimento do trecho i; $\mathrm{P}\left(\mathrm{D}_{\mathrm{i}}\right)$ é a função que relaciona o preço unitário do tubo do trecho i com o diâmetro $\mathrm{D}_{\mathrm{i}}$; $\mathrm{m}$ é o número de trechos da rede; Fa é o fator, ou coeficiente, de atualização do custo de operação; $C_{h}$ é o custo de operação da estação de bombeamento, por unidade de altura manométrica e $\mathrm{H}$ é a altura manométrica de bombeamento.

De acordo com conceitos básicos de matemática financeira, o coeficiente de atualização Fa é dado por:

$$
F_{a}=\frac{(1+e)^{n}-(1+i)^{n}}{(1+e)-(1+i)} \times \frac{1}{(1+i)^{n}}
$$

onde i é a taxa de juros anuais; e é a taxa de aumento anual da energia; $n$ é o número de anos da vida útil da instalação.

Em função da equação básica de potência de conjuntos elevatórios, o custo energético da estação de bombeamento, por altura de impulsão $\left(C_{h}\right)$, pode ser expresso por:

$$
\mathrm{C}_{\mathrm{h}}=\frac{9,81 \mathrm{Q}}{\eta} \mathrm{n}_{\mathrm{b}} \mathrm{p}
$$

onde $Q$ é a vazão em $\mathrm{m}^{3} / \mathrm{s} ; \eta$ o rendimento esperado do conjunto motor-bomba; $\mathrm{n}_{\mathrm{b}} \mathrm{o}$ número de horas anuais de utilização da estação de bombeamento; $p$ é o preço do kwh.

Existem diversos trabalhos que procuram relacionar o custo da tubulação com o seu diâmetro, através de uma equação ou fórmula fixa. No entanto, a melhor maneira de estabelecer essa relação de custo é através de programas computacionais de ajustes de curvas, que permitem, facilmente, testar vários tipos de funções.

A Equação (1), com o critério de custo mínimo, representa a função objetivo do método proposto, cujas variáveis de decisão são os diâmetros contínuos $\mathrm{D}_{\mathrm{i}}$, a altura manométrica de bombeamento $H$, e as vazões nos trechos $Q_{i}$.

\section{Restrições}

A solução ótima (de custo mínimo) a ser obtida, que fornece os diâmetros de todos os trechos da rede e a altura manométrica da estação de

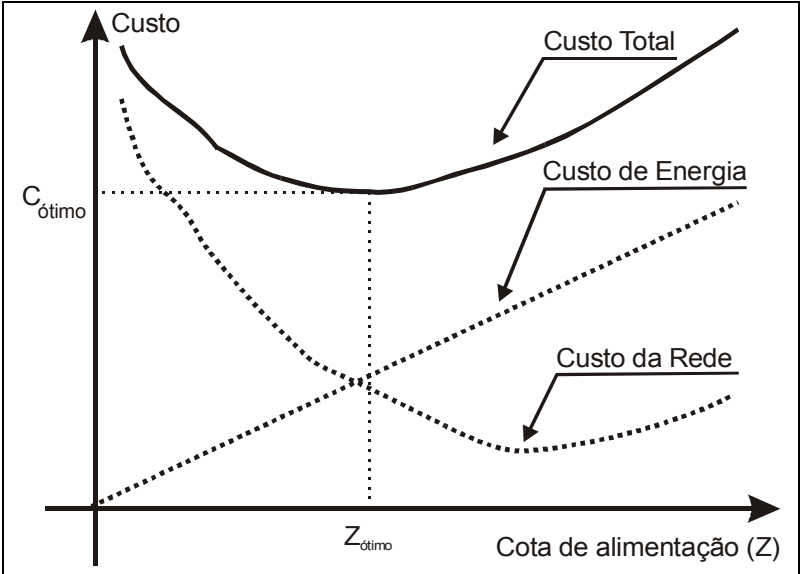

Figura 1. Representação da variação do custo do sistema de abastecimento com a cota de alimentação (Gomes, 1999).

bombeamento, deve satisfazer um conjunto de restrições hidráulicas, que são inerentes ao problema físico de redes malhadas de abastecimento:

a. Pressões mínimas nos nós:

As pressões nos nós da rede não devem ser inferiores às requeridas $\left(Z_{k}\right)$, de modo a garantir $o$ abastecimento aos pontos de consumo:

$$
\mathrm{Z}-\sum_{\mathrm{c}=1}^{\mathrm{k}} \mathrm{J}_{\mathrm{c}} \geq \mathrm{Z}_{\mathrm{k}}
$$

onde $\mathrm{Z}$ é a cota de alimentação na rede, que é igual à altura manométrica de bombeamento " $\mathrm{H}$ " mais a cota do terreno na estação de bombeamento; $Z_{\mathrm{k}}$ é a cota piezométrica requerida no nó " $k$ "; $\Sigma \mathrm{J}_{\mathrm{c}}$ é a soma das perdas de carga nos trechos pertencentes ao percurso (artéria) compreendido entre a alimentação e o nó " $k$ ".

b. Diâmetros mínimos e máximos:

Os diâmetros $\mathrm{D}_{\mathrm{i}}$ devem ser maiores que um diâmetro mínimo $\left(\mathrm{D}_{\mathrm{min}}\right)$ adotado e menores que um diâmetro máximo estimado $\left(\mathrm{D}_{\max }\right)$.

$$
\mathrm{D}_{\min } \leq \mathrm{D}_{\mathrm{i}} \leq \mathrm{D}_{\max }
$$

c. Conservação de energia no anel:

Essa restrição deve garantir que a soma algébrica das perdas de carga dos trechos de um anel seja nula.

$$
\sum_{i=1}^{z_{k}} J_{i}-\sum_{j=1}^{p_{k}} E p_{j}=0
$$


onde $\mathrm{J}_{\mathrm{i}}$ é a perda de carga no trecho $\mathrm{i}$; $\mathrm{z}_{\mathrm{k}}$ é o número de trechos no anel k em questão; $E p_{j}$ é a energia de impulsão aplicada na malha ou anel. Na falta de uma fonte externa dessa energia no interior do anel, o valor de $\Sigma \mathrm{E}_{\mathrm{p}}$ será nulo; $\mathrm{p}_{\mathrm{k}}$ é o número de fontes de energia de impulsão dentro do anel $\mathrm{k}$.

\section{d. Continuidade nos nós:}

A soma algébrica das vazões nos nós deve ser igual a zero, ou seja, as vazões que entram devem ser iguais às que saem:

$$
\sum_{i=1}^{k_{n}} Q_{e^{n} t r a}-\sum_{j=1}^{q_{n}} Q_{\text {sai }_{j}}=d_{n}
$$

onde $Q_{\text {entra (i) }}$ são as vazões dos trechos i que chegam ao nó $n$; $Q_{\text {sai }(j)}$ são as vazões dos trechos $j$ que deixam o nó $\mathrm{n} ; \mathrm{d}_{\mathrm{n}}$ é a demanda concentrada nesse nó; $\mathrm{k}_{\mathrm{n}}$ é o número de trechos com vazões chegando ao nó $\mathrm{n} ; \mathrm{q}_{\mathrm{n}}$ é o número de trechos com vazões saindo do nó n.

e. Velocidades mínima e máxima admissíveis: A rede deve funcionar com velocidades de água limitadas, de forma a se evitar a ocorrência de golpes de aríete, vibrações, como também o desgaste prematuro do sistema. Algumas normas técnicas recomendam também que as velocidades da água nos trechos devem ser superiores a um mínimo adotado.

$$
\mathrm{V}_{\min } \leq \mathrm{V}_{\mathrm{i}} \leq \mathrm{V}_{\max }
$$

onde $\mathrm{V}_{\mathrm{i}}$ é a velocidade média no trecho $\mathrm{i} ; \mathrm{V}_{\max }$ é a velocidade máxima admissível; $\mathrm{V}_{\text {mín }}$ é a velocidade mínima recomendada.

\section{DIMENSIONAMENTO DEFINITIVO (SEGUNDA ETAPA)}

\section{Função objetivo}

A partir dos resultados obtidos no prédimensionamento, executa-se a segunda etapa do PNL2000. Assim, para cada trecho, o diâmetro ótimo contínuo, obtido na primeira etapa, é desdobrado em dois diâmetros comerciais, sendo um o imediatamente superior, e o outro o imediatamente inferior àquele encontrado. Dessa forma, a função objetivo a ser minimizada será:

$$
\mathrm{C}\left(1_{\mathrm{ij}}, \mathrm{Q}_{\mathrm{i}}, \mathrm{H}\right)=\sum_{\mathrm{i}=1 \mathrm{j}=1}^{\mathrm{m}} \sum_{\mathrm{ij}}^{2} \mathrm{P}\left(\mathrm{D}_{\mathrm{j}}\right)_{\mathrm{i}}+\mathrm{C}_{\mathrm{h}} \mathrm{HFa}
$$

onde $1_{i j}$ é o comprimento ocupado pelo diâmetro $D_{j}$ no trecho i considerado; $\mathrm{P}\left(\mathrm{D}_{\mathrm{j}}\right)_{\text {i }}$ é o preço unitário do tubo de diâmetro $D_{j}$ no trecho $\mathrm{i}$; $\mathrm{m}$ é o número de trechos da rede.

A função objetivo (9) tem como variáveis de decisão os comprimentos dos sub-trechos $1_{\mathrm{ij}}$ e a altura de bombeamento $\mathrm{H}$, sendo que as vazões nos trechos continuam sendo variáveis do processo de otimização.

Nessa etapa, as vazões poderiam ser mantidas fixas (com os valores obtidos na primeira etapa), e as variáveis do modelo seriam os comprimentos dos sub-trechos e a altura manométrica de bombeamento. No entanto, a solução assim obtida (através do processo de otimização) seria uma solução factível, mas seu valor superior ao ótimo, quando se considera as vazões como variáveis de decisão do modelo. Isso acontece devido a uma peculiaridade do modelo matemático da programação não linear, que permite um maior número de possíveis soluções quanto maior for o número de variáveis de decisão.

\section{Restrições}

As restrições "a", "b", "c" "d" e "e" da etapa inicial também devem ser satisfeitas nesta fase. Além dessas, a solução encontrada deve satisfazer a mais dois grupos de restrições, que são:

f. Comprimento dos sub-trechos:

$$
\sum_{j=1}^{2} 1_{i j}=L_{i}
$$

g. Não negatividade dos comprimentos dos sub-trechos:

$$
1_{\mathrm{ij}} \geq 0
$$

Na resposta definitiva do dimensionamento ótimo deverá haver algum ou alguns trechos com tubulações de dois diâmetros comerciais distintos, sendo que o de diâmetro maior ocupará o sub-trecho de montante (considerando o sentido do fluxo de água estabelecido pela vazão) e o menor o sub-trecho de jusante. 
RBRH - Revista Brasileira de Recursos Hídricos Volume 6 n.4 Out/Dez 2001, 91-108

\section{EXEMPLO DE APLICAÇÃO DO MÉTODO}

\section{Enunciado do problema}

O exemplo escolhido corresponde ao do sistema de abastecimento de água de um grande setor de um bairro da cidade de João Pessoa, projetado pela Companhia de abastecimento d'água da Paraíba - CAGEPA, em 1982 (CAGEPA, 1982). A rede de abastecimento do Grande Setor é composto por dois anéis, alimentados por um reservatório elevado, conforme mostra o esquema apresentado na Figura 2. Pretende-se dimensionar neste exemplo, com o menor custo possível, todos os trechos da rede e a altura do reservatório elevado, levandose em consideração os preços de implantação das tubulações e o custo de operação (energético) do conjunto motor-bomba, que impulsionará a água para o reservatório. O nível da água de captação (poço de sucção) está na cota 30 (em metros), que coincide com a cota altimétrica do terreno.

A Tabela 1 apresenta as demandas e as cotas altimétricas do terreno nos nós dos anéis em questão, enquanto que a Tabela 2 fornece os dados referentes aos comprimentos dos trechos dos anéis.

A pressão mínima imposta aos nós do Grande Setor é de $25 \mathrm{mca}$, e as velocidades máximas e mínimas admitidas nos trechos da rede são de $3,0 \mathrm{~m} / \mathrm{s}$ e $0,2 \mathrm{~m} / \mathrm{s}$, respectivamente.

Na Figura 2 se encontram também os sentidos de escoamento admitidos para as vazões e a numeração dos nós e dos trechos da rede.

O material da tubulação usada no sistema é de ferro dúctil para tubos de diâmetros superiores a $300 \mathrm{~mm}$ e de PVC para diâmetros situados entre 100 e $300 \mathrm{~mm}$. Os tubos de PVC rígido, são do tipo DEFoFo (diâmetros externos idênticos aos de ferro fundido), fabricados de acordo com a norma NBR 7665 da ABNT, dimensionados para trabalhar com água a $20^{\circ} \mathrm{C}$ e pressões de serviço máximas de $1 \mathrm{MPa}$ (100 mca), incluindo as variações dinâmicas. Os tubos de ferro dúctil são da Classe K-7, cujas pressões máximas de serviço são de 1,9 MPa para o diâmetro de $350 \mathrm{~mm}$ e de 1,8 MPa para os diâmetros entre 400 e $600 \mathrm{~mm}$. Os coeficientes de rugosidade " $\mathrm{C}$ ", da fórmula de Hazen-Williams, que serão utilizados nos cálculos das perdas de carga, são de 145, para os tubos de PVC, e de 130 para os de ferro dúctil. A Tabela 3 fornece os preços unitários de implantação dos tubos (em Reais por metro) e os diâmetros internos, em função dos seus diâmetros nominais.
Tabela 1. Vazões demandadas e cotas dos nós.

\begin{tabular}{ccc}
\hline Nó & Vazão $(1 / \mathrm{s})$ & Cota $(\mathrm{m})$ \\
\hline 1 & 0,00 & 6,0 \\
2 & 47,78 & 5,5 \\
3 & 80,32 & 5,5 \\
4 & 208,60 & 6,0 \\
5 & 43,44 & 4,5 \\
6 & 40,29 & 4,0 \\
\hline
\end{tabular}

Tabela 2. Comprimentos dos trechos.

\begin{tabular}{cc}
\hline Trecho & Comprimento $(\mathrm{m})$ \\
\hline 1 & 2.540 \\
2 & 1.230 \\
3 & 1.430 \\
4 & 1.300 \\
5 & 1.490 \\
6 & 1.210 \\
7 & 1.460 \\
8 & 1.190 \\
\hline
\end{tabular}

Tabela 3. Preço de implantação dos tubos (em Reais por metro).

\begin{tabular}{cccc}
\hline $\begin{array}{c}\text { Diâmetro } \\
\text { nominal } \\
(\mathrm{mm})\end{array}$ & $\begin{array}{c}\text { Material } \\
\text { do tubo }\end{array}$ & $\begin{array}{c}\text { Diâmetro } \\
\text { interno } \\
(\mathrm{mm})\end{array}$ & $\begin{array}{c}\text { Custo de } \\
\text { implantação } \\
(\mathrm{R} \$ / \mathrm{m})\end{array}$ \\
\hline 100 & PVC & 108,4 & 32,80 \\
150 & “ & 156,4 & 43,41 \\
200 & “ & 204,2 & 59,24 \\
250 & “ & 252,0 & 78,52 \\
300 & “ & 299,8 & 103,12 \\
350 & FoFo & 381,0 & 225,82 \\
400 & " & 432,0 & 267,66 \\
450 & “ & 483,0 & 302,63 \\
500 & “ & 535,0 & 349,29 \\
600 & “ & 638,0 & 433,37 \\
\hline
\end{tabular}

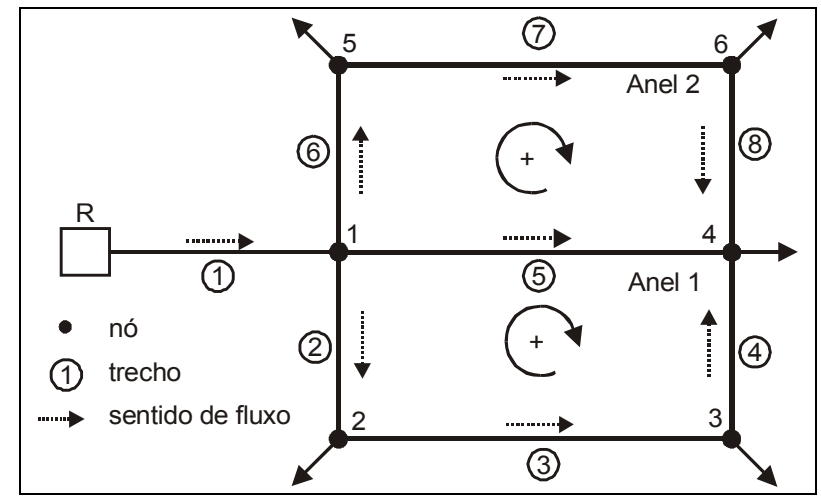

Figura 2. Esquema do Grande Setor. 
O dimensionamento será efetuado considerando as condições de contorno bem estabelecidas, com relação ao fornecimento da água no reservatório de alimentação. A altura manométrica, ou altura do reservatório elevado, será considerada variável de decisão, com o propósito de se otimizar também a altura do reservatório em relação ao nível do terreno.

No caso do dimensionamento econômico com o nível de água do reservatório a ser determinado, faz-se necessário conhecer os dados sobre o bombeamento do sistema. Os custos e regime do bombeamento utilizados foram:

- número de horas de bombeamento diário = 20;

- rendimento esperado do conjunto motorbomba $=75 \%$;

- tempo de vida útil do projeto = 20 anos;

- $\quad$ taxa de juro anual = $12 \%$;

- taxa de aumento anual da energia $=6 \%$; e

- custo do kwh (incluindo a tarifa de demanda) $=R \$ 0,071$.

\section{Resolução do exemplo}

Para as formulações das funções objetivo faz-se necessário determinar inicialmente:

- a equação que relaciona a variação do preço da tubulação com o diâmetro;

- o custo unitário de operação da estação elevatória;

- o fator de atualização "Fa".

A equação que relaciona o custo de implantação da tubulação P (D), com o seu diâmetro " $\mathrm{D}$ ", pode ser obtida através de um ajuste de curva (ver Figura 3) executado pela ferramenta "linha de tendência" da planilha Excel. A equação obtida, a partir dos dados da Tabela 3 (coluna 6versus coluna 3), foi:

$$
P(D)=0,0129 \times D^{1,6165}
$$

O custo unitário de operação da estação elevatória pode ser determinado através da Equação (3), ou seja:

$$
\begin{gathered}
\mathrm{C}_{\mathrm{h}}=\frac{9,81 \times 0,4204 \times 20 \times 365 \times 0,071}{0,75}= \\
2.850,04 \mathrm{R} \$ / \mathrm{m} / \mathrm{ano}
\end{gathered}
$$

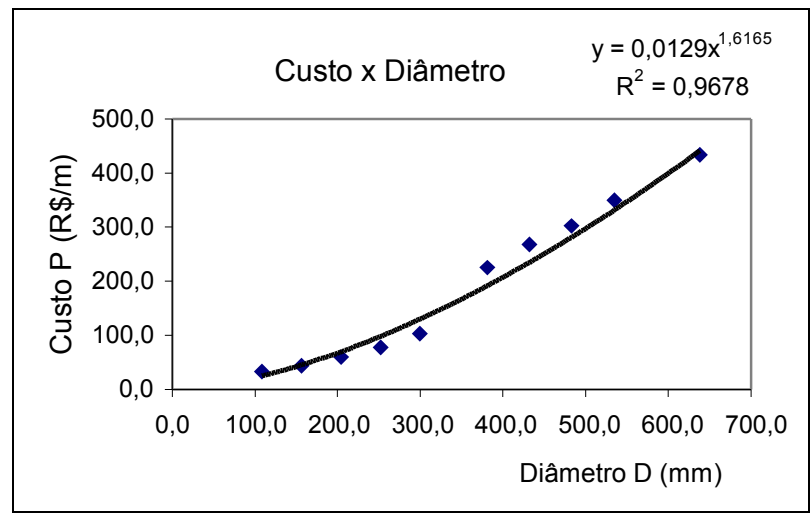

Figura 3. Curva de ajuste do custo de implantação das tubulações versus diâmetro do tubo.

Para uma taxa de juros anuais de $12 \%$, taxa de aumento da energia de $6 \%$, e vida útil das instalações de 20 anos, o coeficiente de atualização será (ver Equação 2):

$$
F_{a}=\frac{(1+0,06)^{20}-(1+0,12)^{20}}{(1+0,06)-(1+0,12)} \times \frac{1}{(1+0,12)^{20}}=11,13
$$

\section{ETAPA 1}

\section{Função objetivo da etapa 1}

A função objetivo correspondente ao custo total atualizado do sistema de abastecimento, será:

$\mathrm{C}\left(\mathrm{D}_{\mathrm{i}}, \mathrm{Q}_{\mathrm{i}}, \mathrm{H}\right)=\left[2.540 \mathrm{P}\left(\mathrm{D}_{1}\right)+1.230 \mathrm{P}\left(\mathrm{D}_{2}\right)+1.430\right.$

$\mathrm{P}\left(\mathrm{D}_{3}\right)+1.300 \mathrm{P}\left(\mathrm{D}_{4}\right)+1.490 \mathrm{P}\left(\mathrm{D}_{5}\right)+1.210 \mathrm{P}\left(\mathrm{D}_{6}\right)$ $\left.+1.460 \mathrm{P}\left(\mathrm{D}_{7}\right)+1.190 \mathrm{P}\left(\mathrm{D}_{8}\right)\right]+(2.850,04 \times 11,13 \times \mathrm{H})$

Substituindo $\mathrm{P}\left(\mathrm{D}_{\mathrm{i}}\right)$ pela Expressão (12) tem-se:

$\mathrm{C}\left(\mathrm{D}_{\mathrm{i}}, \mathrm{Q}_{\mathrm{i}}, \mathrm{H}\right)=\left[2.540 \times 0,0129\left(\mathrm{D}_{1}\right)^{1,6165}+1.230 \times\right.$ $0,0129\left(\mathrm{D}_{2}\right)^{1,6165}+1.430 \times 0,0129\left(\mathrm{D}_{3}\right)^{1,6165}+1.300 \times$ $0,0129\left(\mathrm{D}_{4}\right)^{1,6165}+1.490 \times 0,0129\left(\mathrm{D}_{5}\right)^{1,6165}+1.210 \times$ $0,0129\left(\mathrm{D}_{6}\right)^{1,6165}+1.460 \times 0,0129\left(\mathrm{D}_{7}\right)^{1,6165}+1.190 \times$ $\left.0,0129\left(\mathrm{D}_{8}\right)^{1,6165}\right]+(2.850,04 \times 11,13 \times \mathrm{H})$

\section{Restrições da etapa 1}

a. Pressão mínima:

A restrição de pressão mínima impõe que em todos os nós da rede a pressão disponível seja maior ou igual a 25 mca. Ou seja, para um determinado nó da rede, a cota piezométrica no reservató- 
rio (em metros), menos as perdas de carga dos trechos situados em série, num percurso entre a origem e o nó considerado (em metros), deve ser maior ou igual a $25 \mathrm{mca}$, mais a cota topográfica do nó (em metros).

A cota piezométrica do reservatório " $\mathrm{Z}$ " do Grande Setor é igual a altura manométrica " $\mathrm{H}$ " a ser determinada, mais a cota do terreno na origem, que é de 30 metros, ou seja:

$$
\begin{aligned}
& Z=H+K \\
& Z=H+30
\end{aligned}
$$

A equação de perda de carga total (J), ao longo do conduto, a ser utilizada neste exemplo, será a de Hazen-Williams:

$$
\mathrm{J}=10,66\left(\frac{\mathrm{Q}}{\mathrm{C}}\right)^{1,852} \frac{\mathrm{L}}{\mathrm{D}^{4,87}}
$$

A forma mais precisa para o cálculo das perdas de carga contínuas nas tubulações é com o emprego da fórmula Universal. No entanto, optouse pela utilização da equação de Hazen-Williams pelos motivos apresentados a seguir. Em primeiro lugar, os resultados obtidos neste trabalho, através do dimensionamento otimizado, serão comparados com os resultados obtidos no dimensionamento original do Grande Anel (CAGEPA, 1982), cujos cálculos das perdas de carga contínuas foram executados com o uso da fórmula de Hazen-Williams, com os valores do coeficiente de rugosidade " $\mathrm{C}$ " iguais a 130 e 145 , para tubos de ferro fundido e PVC, respectivamente. Em segundo lugar, o método de otimização apresentado requer a realização, de forma iterativa, de centenas de cálculos da perda de carga contínua, em função das variáveis de decisão do modelo (vazão e diâmetro). Nesse caso, a ferramenta Solver do Excel não seria operativa para a obtenção da solução ótima, com o emprego da fórmula Universal, mesmo para redes de pequeno porte. Pode-se acrescentar também que em projetos de redes de abastecimento pressurizadas, a precisão que se pode ganhar com o emprego da fórmula Universal será diluída com a imprecisão na obtenção da rugosidade dos tubos, já que não se pode garantir uma adequada uniformidade e precisão de fabricação das paredes internas dos diferentes tubos disponíveis no mercado. Acrescenta-se também que no cálculo das perdas totais nas redes de abastecimento de água, existem ainda as imprecisões na determinação das perdas de carga localizadas das peças especiais, como também as imprecisões nas perdas de energia devido às diferenças de cotas altimétricas, quando do assentamento das tubulações enterradas.

Ao todo, serão seis equações de restrição de pressão, sendo uma para cada nó. Para qualquer nó da rede, a queda de pressão entre o reservatório de alimentação e o nó considerado será a mesma, independente do percurso escolhido entre a alimentação e o nó. No caso do nó 4, por exemplo, pode-se escolher qualquer caminho entre o reservatório elevado e o nó (trechos 1, 2, 3 e 4; 1, 6, 7 e 8 ou 1 e 5). É conveniente escolher o caminho mais curto a fim de diminuir o tamanho da equação de restrição. No caso do nó 4, adotou-se o caminho através dos trechos 1 e 5 . Assim, a restrição de pressão mínima no nó 4 será:

$$
\mathrm{Z}-\left(\mathrm{J}_{1}+\mathrm{J}_{5}\right) \geq(25+6,0)
$$

Introduzindo as expressões de perda de carga tem-se:

$$
\begin{aligned}
& (\mathrm{H}+30)-10,66\left(\frac{\mathrm{Q}_{1}}{\mathrm{C}_{1}}\right)^{1,852} \frac{2.540}{\mathrm{D}_{1}^{4,87}}- \\
& 10,66\left(\frac{\mathrm{Q}_{5}}{\mathrm{C}_{5}}\right)^{1,852} \frac{1.490}{\mathrm{D}_{5}^{4,87}} \geq(25+6)
\end{aligned}
$$

As outras equações de restrição de pressão mínima serão:

$$
\begin{gathered}
\text { Nó } 1: \mathrm{Z}-\left(\mathrm{J}_{1}\right) \geq(25+6,0) \\
\text { Nó } 2: \mathrm{Z}-\left(\mathrm{J}_{1}+\mathrm{J}_{2}\right) \geq(25+5,5) \\
\text { Nó 3: } \mathrm{Z}-\left(\mathrm{J}_{1}+\mathrm{J}_{2}+\mathrm{J}_{3}\right) \geq(25+5,5) \\
\text { Nó 5: } \mathrm{Z}-\left(\mathrm{J}_{1}+\mathrm{J}_{6}\right) \geq(25+4,5) \\
\text { Nó 6: } \mathrm{Z}-\left(\mathrm{J}_{1}+\mathrm{J}_{6}+\mathrm{J}_{7}\right) \geq(25+4,0)
\end{gathered}
$$

b. Restrição de diâmetros:

Todos os diâmetros devem ser maiores do que $108,4 \mathrm{~mm}$ e menores que $638,0 \mathrm{~mm}$, que é a faixa de diâmetros disponível para o projeto. Como são 8 trechos e cada trecho possui duas restrições, tem-se 16 restrições de diâmetros:

$$
\begin{aligned}
& \mathrm{D}_{1} \geq 108,4 ; \ldots \mathrm{D}_{8} \geq 108,4 \\
& \mathrm{D}_{1} \leq 638,0 ; \ldots \mathrm{D}_{8} \leq 638,0
\end{aligned}
$$


c. Conservação de energia nos anéis:

A rede é composta por dois anéis, havendo portanto duas equações de restrição de conservação de energia. Serão consideradas como positivas as perdas em que o sentido da vazão é o mesmo que o arbitrado para o anel (no caso contrário as perdas serão negativas). Dessa forma tem-se:

$$
\begin{aligned}
& \text { Anel 1: }\left(\mathrm{J}_{5}-\mathrm{J}_{2}-\mathrm{J}_{3}-\mathrm{J}_{4}\right)=0 \\
& \text { Anel 2: }\left(\mathrm{J}_{6}+\mathrm{J}_{7}+\mathrm{J}_{8}-\mathrm{J}_{5}\right)=0
\end{aligned}
$$

d. Continuidade nos nós:

Ao todo são 6 nós, havendo portanto 6 equações de restrição desse tipo. Tomando-se as vazões em 1/s, as equações de restrição serão:

Para o nó 1, que não possui demanda:

$$
\left(Q_{1}-Q_{2}-Q_{5}-Q_{6}\right)=0
$$

Para o nó 2, que possui uma demanda de $47,781 / \mathrm{s}:$

$$
\left(Q_{2}-Q_{3}\right)=47,78
$$

Para o nó 3:

$$
\left(Q_{3}-Q_{4}\right)=80,32
$$

Para o nó 4:

$$
\left(Q_{4}+Q_{5}+Q_{8}\right)=208,6
$$

Para o nó 5:

$$
\left(Q_{6}-Q_{7}\right)=43,44
$$

Para o nó 6:

$$
\left(\mathrm{Q}_{7}-\mathrm{Q}_{8}\right)=40,29
$$

e. Velocidades máximas e mínimas adotadas:

$$
\begin{aligned}
& \mathrm{V}_{1} \geq 0,2 \mathrm{~m} / \mathrm{s} ; \ldots \mathrm{V}_{8} \geq 0,2 \mathrm{~m} / \mathrm{s} \\
& \mathrm{V}_{1} \leq 3,0 \mathrm{~m} / \mathrm{s} ; . . \mathrm{V}_{8} \leq 3,0 \mathrm{~m} / \mathrm{s}
\end{aligned}
$$

\section{Resolução do modelo através da ferramenta Solver da planilha Excel}

A obtenção do dimensionamento ótimo de redes de abastecimento, através do modelo da pro- gramação não linear apresentado, pode ser resolvido com o emprego de aplicativos informáticos de computação numérica, tais como o MATLAB, GAMES, MINUS, etc. No entanto, optou-se neste trabalho pela utilização da ferramenta Solver, do aplicativo Excel da Microsoft, pelas facilidades de edição das inúmeras equações requeridas pelo modelo. A versatilidade que a planilha Excel possui de editar operações e formulações matemáticas, proporciona ao usuário rapidez e facilidade na edição de problemas numéricos. Existe ainda a vantagem do projetista poder visualizar, em uma planilha, a simulação do comportamento hidráulico de uma rede pressurizada de abastecimento, submetida a diferentes condições de projeto ou de operação.

\section{Edição da planilha da etapa 1}

Montadas as equações que envolvem o problema, pode-se editá-las na planilha eletrônica do Excel, a fim de se obter o dimensionamento otimizado da rede. Na planilha mostrada na Figura 4 estão preenchidos todos os dados necessários ao processo de otimização da primeira etapa do dimensionamento do Grande Setor. Como pode ser observado, para melhor visualização dos resultados, essa planilha está dividida em três partes: Planilha da função objetivo, onde se localizam os dados sobre os trechos da rede, as equações referentes às perdas de carga, custo dos tubos, etc.; Planilha das equações de restrição, onde se localizam as células que contém os resultados derivados das equações de restrição e Planilha dos custos conjuntos, onde são determinados os custos da energia capitalizada, e o custo total do sistema de abastecimento, a ser minimizado.

O significado das colunas da planilha (Figura 4) são:

Coluna B: Número do trecho (dados inseridos).

Coluna C: Vazão no trecho. Dados inicialmente atribuídos e que são variáveis a serem ajustadas hidraulicamente no processo de otimização. O conjunto de dados de vazão deve ser atribuído em função das demandas dos nós da rede, garantindo-se que a vazão no trecho de origem deve ser igual à soma de todas as demandas da rede.

Para se atribuir uma solução inicial de vazões nos trechos da rede, pode-se aplicar a seguinte regra: Parte-se de um nó extremo (por exemplo o 


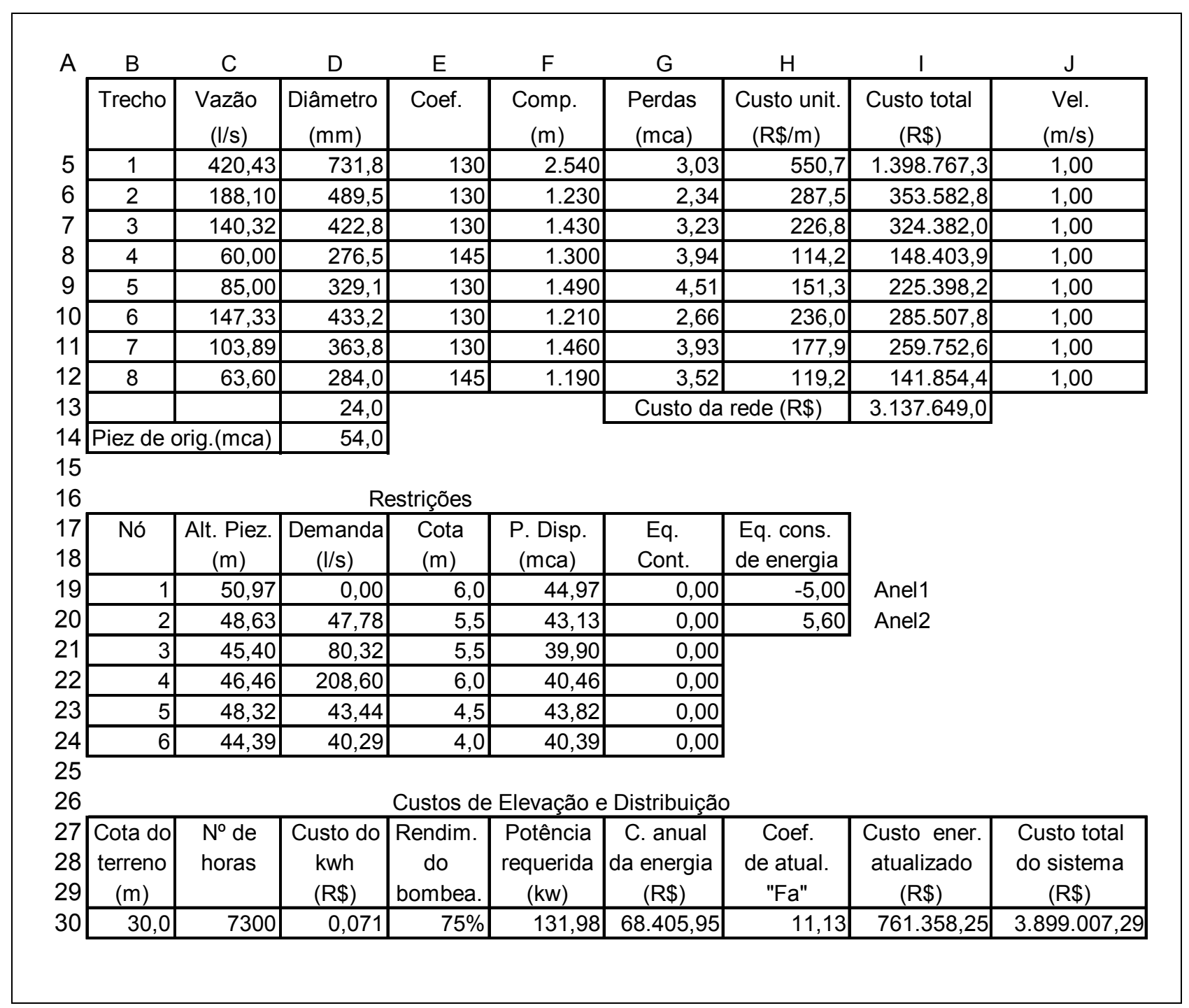

Figura 4. Dimensionamento do Grande Setor - primeira etapa - solução inicial.

nó 4) e, respeitando-se o princípio de conservação de massa nos nós e os sentidos das vazões inicialmente arbitrados, vai-se somando, de jusante para montante, as demandas dos nós da rede com as vazões dos trechos de jusante, até ser alcançada a descarga do trecho de origem. A vazão do trecho de origem será, obviamente, a descarga total demandada pela rede.

Coluna D: Diâmetro a ser utilizado no trecho (variável de decisão a ser otimizada). Inicialmente esses dados devem ser atribuídos para fazerem parte, juntamente com as vazões, da solução inicial do problema. Uma forma de se atribuir valores iniciais para os diâmetros pode ser mediante a admissão, por exemplo, de uma velocidade média de escoamento de $1 \mathrm{~m} / \mathrm{s}$. Dessa forma os valores dos diâmetros iniciais serão determinados através da equação da continuidade, e dos valores das vazões iniciais já definidos.

Na célula \$D 13 se encontra a altura manométrica de bombeamento a ser otimizada, cujo valor adotado para essa variável, na solução inicial, foi de 24 metros de coluna de água.

Na célula \$D $\$ 14$ tem-se a cota piezométrica da alimentação da rede: $=30+$ D13

Coluna E: Coeficiente de Hazen-Williams. Para diâmetros menores do que $300 \mathrm{~mm}$ (tubo de PVC), o coeficiente adotado foi de 145, e para iguais ou maiores do que $300 \mathrm{~mm}$ (tubo de ferro dúctil), o coeficiente foi de 130. Esses dados são inseridos na planilha através do condicionante "SE". A célula E5 será: $=$ SE (D5 < = 300;145;130). As células E6, E7,..., E12 são preenchidas automaticamente, através da fórmula já definida para a célula E5. 
Coluna F: Comprimentos dos trechos (valores atribuídos segundo os dados do projeto - ver Tabela 2);

Coluna G: Perda de carga no trecho. Se a vazão for negativa, o sentido arbitrado inicialmente para essa variável será o contrário e a perda no trecho será computada com o sinal negativo. Para que a perda possa ser calculada com o valor negativo da vazão, na equação da perda deve aparecer o sinal negativo antes do valor de $Q$, para que seja evitada uma indeterminação matemática (valor negativo elevado a uma potência). A célula G5 será: $=\mathrm{SE}\left(\mathrm{C} 5>=0 ; 10,66^{*} \mathrm{~F}^{*}((\mathrm{C} 5 / 1000) / \mathrm{E} 5) \wedge 1,852 /\right.$ $\left((\mathrm{D} 5 / 1000)^{\wedge} 4,87\right) ;-10,66 * \mathrm{~F}^{*}((-\mathrm{C} 5 / 1000) / \mathrm{E} 5)^{\wedge} 1,852$ $\left./\left((\mathrm{D} 5 / 1000)^{\wedge} 4,87\right)\right)$.

Coluna H: Custo unitário, obtido a partir da equação que relaciona preço do tubo com o diâmetro (Equação 12). A célula H5 será: $=0,0129^{*}\left(\mathrm{D} 5^{\wedge} 1,6165\right)$.

Coluna I: Custo total do trecho, que é igual ao custo unitário do tubo do diâmetro utilizado, vezes o comprimento do trecho. A célula I5 será: $=\mathrm{H} 5 * \mathrm{~F} 5$

Na célula \$I $\$ 13$ se encontra o custo total da rede, que é igual ao somatório das células \$I\$5:\$I\$12.

Coluna J: Velocidade - é igual à velocidade média na seção do tubo em um determinado trecho. A célula J5 será:

$$
=(4 / 3,14)^{*}(\mathrm{C} 5 / 1000) /\left((\mathrm{D} 5 / 1000)^{\wedge} 2\right)
$$

Na parte da planilha referente às restrições (ainda na Figura 4) os significados das colunas são:

Coluna B: Número do nó (valores atribuídos de projeto).

Coluna C: Cota piezométrica disponível no nó, obtida a partir das equações de restrição do tipo 1.

A célula C19 será: $=$ D14-G5;

A célula C20: $=$ C19-G6;

A célula C21: $=\mathrm{C} 20-\mathrm{G} 7 ;$

A célula C22: $=$ C19-G9;

A célula C23: $=$ C19-G10;

A célula C24: $=$ C23-G11.

Coluna D: Demanda no nó (valores atribuídos - ver Tabela 1).

Coluna E: Cota altimétrica do nó (valores atribuídos - ver Tabela 1).

Coluna F: Pressão disponível no nó, que é igual à altura piezométrica menos a cota do terreno. A célula F19 será: = C19-E19.
Coluna G: Equação da continuidade, obtida a partir das equações de restrição do tipo "d" (Equações $26, \ldots, 31$ ).

A célula G19 será: = C5-C6-C9-C10;

G20 será: $=$ C6-C7-D20;

G21 será: $=$ C7-C8-D21;

G22 será: $=$ C $8+C 12+C 9-D 22$;

G23 será: $=$ C10-C11-D23;

G24 será: = C11-C12-D24.

Coluna H: Conservação de energia (equação de restrição do tipo "c" Equações 24 e 25).

A célula H19 será: = G9-G6-G7-G8.

A célula H20 será: $=$ G10+G11+G12-G9.

Na parte da planilha referente aos custos (ainda na Figura 4) os significados das colunas são:

Coluna B: Cota do terreno da cabeceira da rede (valor atribuído de projeto).

Coluna C: Número anual de horas de bombeamento (valor atribuído de projeto).

Coluna D: Custo do kwh (valor atribuído de projeto).

Coluna E: Rendimento do conjunto motorbomba (valor atribuído de projeto).

Coluna F: Potência do conjunto motorbomba: $=\left(9,81^{*} \mathrm{D} 13^{*}(\mathrm{C} 5 / 1000)\right) / \mathrm{E} 30$.

Coluna G: Custo anual com energi$\mathrm{a}:=\mathrm{F} 30^{*} \mathrm{D} 30^{*} \mathrm{C} 30$.

Coluna H: Coeficiente de atualização da energia (valor calculado através da Equação 2).

Coluna I: Custo atualizado da energi$\mathrm{a}:=\mathrm{H} 30 * \mathrm{G} 30$.

Coluna J: Custo total. Essa célula é a que será minimizada no processo de otimização, através da ferramenta Solver da planilha Excel: = I30+I13.

\section{Processo de otimização e resultados da etapa 1}

Depois de construída a planilha, inicia-se o processo de otimização da rede, através da ferramenta Solver do Excel. Primeiramente deve-se efetuar o preenchimento dos parâmetros, necessários para a otimização, "informando" ao programa a célula em que se encontra a função objetivo (nesse caso a célula \$J \$3), as variáveis de decisão (células \$C\$5:\$D \$13) e as restrições ao problema.

As restrições a serem inseridas na planilha são:

$\$ \mathrm{D} \$ 5: \$ \mathrm{D} \$ 12<=638$

$\$ \mathrm{D} \$ 5: \$ \mathrm{D} \$ 12>=108,4$ 


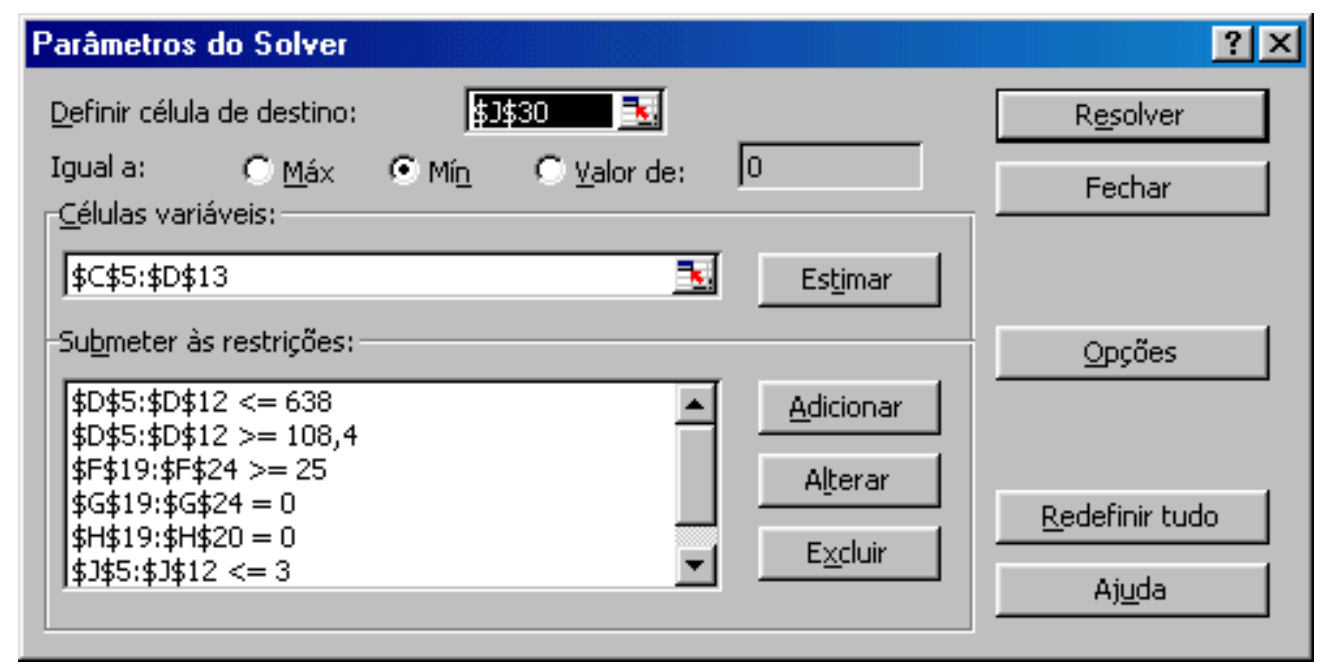

Figura 5. Entrada de parâmetros da ferramenta Solver do Excel da primeira etapa do dimensionamento do Grande Setor.

$$
\begin{aligned}
& \text { \$F\$19:\$F } \$ 24>=25 \\
& \text { \$G\$19:\$G } \$ 24=0 \\
& \text { \$H\$19:\$H } \$ 20=0 \\
& \text { \$J5:\$J } \$ 12>=0,2 \\
& \text { \$J5:\$J } \$ 12<=3,0
\end{aligned}
$$

Como o problema se constitui em minimizar o custo total do sistema de abastecimento, a célula de destino deverá ser igual a Min no quadro de parâmetros do Solver. Os parâmetros do Solver já preenchidos podem ser visualizados através da Figura 5 .

O problema do dimensionamento ótimo é resolvido após pressionando-se "resolver" no quadro de parâmetros da ferramenta Solver.

A fim de assegurar que a solução encontrada é a ótima, é recomendável repetir o processo de otimização mais de uma vez (com valores iniciais distintos das variáveis de decisão), até se chegar à conclusão que o resultado é a solução ótima procurada. O resultado, obtido após as iterações pertinentes, pode ser visto na planilha mostrada na Figura 6, onde o custo mínimo atualizado do sistema (rede mais energia de bombeamento) é de $\mathrm{R} \$ 2.694 .039,72$.

Nas células D5:D12, da planilha (Figura 6), estão os diâmetros ótimos encontrados na primeira etapa do processo de otimização. Na célula D13 está a altura manométrica de bombeamento ótima, cujo valor encontrado foi de 21,7 metros. Os valores ótimos das demais variáveis de decisão (vazão e diâmetro) encontram-se nas colunas C e D da planilha (Figura 6).

\section{ETAPA 2}

De posse dos resultados dos diâmetros, vazões e altura manométrica obtidos na etapa 1 do dimensionamento, realiza-se novo processo de otimização, considerando como variáveis a vazão, dois comprimentos para cada trecho e a altura de bombeamento. Para cada trecho serão adotados dois diâmetros comerciais, um imediatamente superior e outro imediatamente inferior ao obtido na primeira etapa. Antes de estabelecer a função objetivo, é preciso definir os diâmetros comercialmente disponíveis para a solução do problema (ver Tabela 4).

\section{Função objetivo da etapa 2}

O custo total do sistema de abastecimento (rede mais energia de bombeamento), que é a função objetivo a ser minimizada, será, conforme as definições apresentadas pela Equação (9):

$\mathrm{C}\left(\mathrm{l}_{\mathrm{i},}, \mathrm{Q}_{\mathrm{i}}, \mathrm{H}\right)=\left[\left(\mathrm{l}_{1,535} \times \mathrm{P}(535)+\mathrm{l}_{1,638} \times \mathrm{P}(638)\right)+\left(\mathrm{l}_{2,299}\right.\right.$ $\left.\times \mathrm{P}(299,8)+1_{2,381} \times \mathrm{P}(381)\right)+\left(1_{3,299} \times \mathrm{P}(299,8)+1_{3,381}\right.$ $\times \mathrm{P}(381))+\left(1_{4,108} \times \mathrm{P}(108,4)+1_{4,156} \times \mathrm{P}(156,4)\right)+$ $\left(1_{5,381} \times \mathrm{P}(381)+1_{5,432} \times \mathrm{P}(432)\right)+\left(1_{6,299} \times \mathrm{P}(299,8)+\right.$ $\left.1_{6,381} \times \mathrm{P}(381)\right)+\left(1_{7,204} \times \mathrm{P}(204,2)+1_{7,252} \times \mathrm{P}(252)+\right.$ $\left.\left(1_{8,108} \times \mathrm{P}(108,4)+1_{8,156} \times \mathrm{P}(156,4)\right)\right]+(2.850,04 \times$ $11,13 \times \mathrm{H})$ 


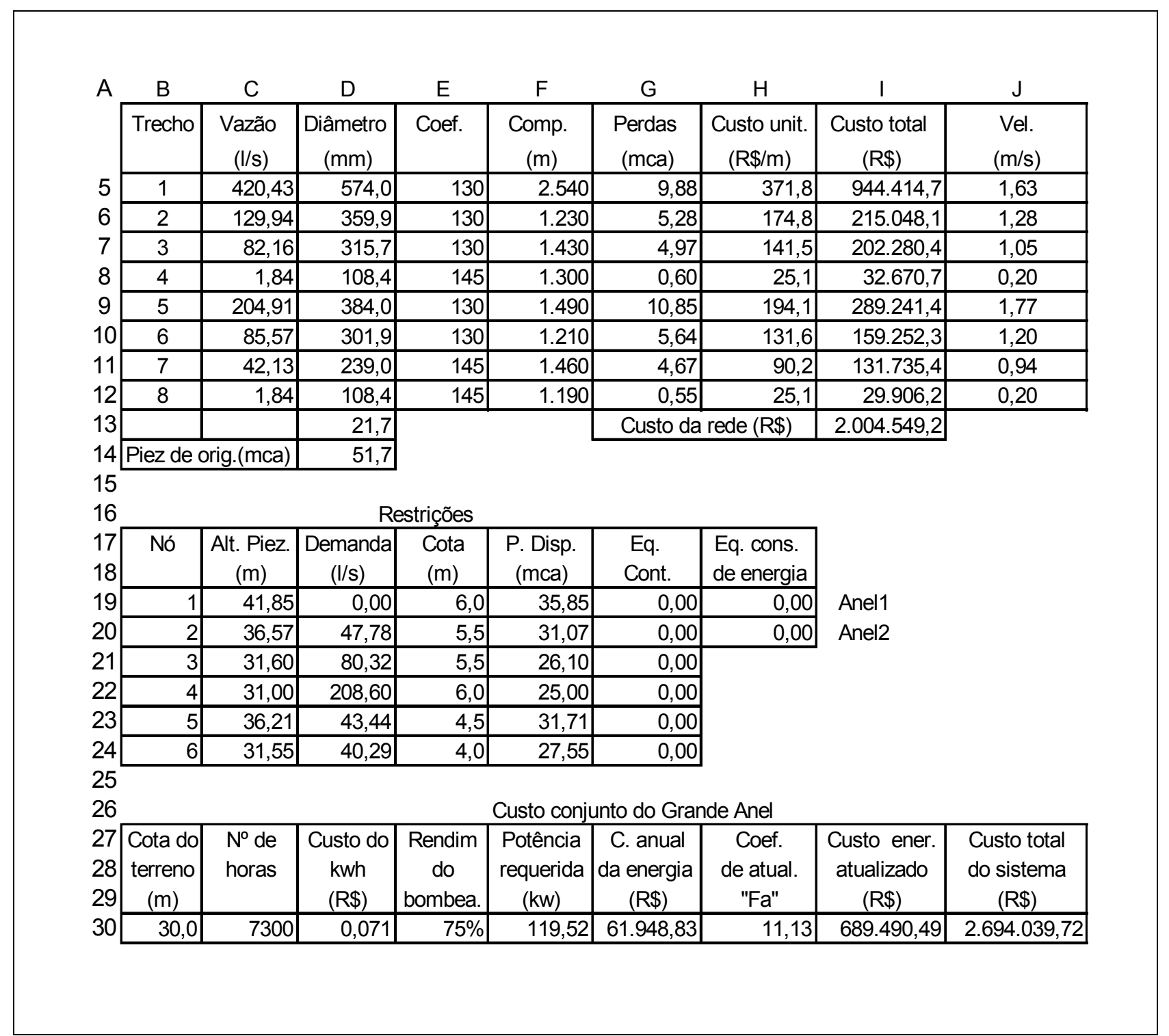

Figura 6. Dimensionamento do Grande Setor - primeira etapa - solução otimizada.

Introduzindo os valores dos preços dos tubos (Tabela 3) tem-se:

$\mathrm{C}\left(\mathrm{l}_{\mathrm{ij},}, \mathrm{Q}_{\mathrm{i}}, \mathrm{H}\right)=\left[\left(349,29 \times \mathrm{l}_{1,535}+433,37 \times \mathrm{l}_{1,638}\right)+\right.$ $\left(103,12 \times 1_{2,299}+225,82 \times 1_{2,381}\right)+\left(103,12 \times 1_{3,299}+\right.$ $\left.225,82 \times 1_{3,381}\right)+\left(32,80 \times 1_{4,108}+43,41 \times 1_{4,156}\right)+(225,82$ $\left.\times 1_{5,381}+267,66 \times 1_{5,432}\right)+\left(103,12 \times 1_{6,299}+225,82 \times\right.$ $\left.1_{6,381}\right)+\left(59,24 \times 1_{7,204}+78,52 \times 1_{7,252}\right)+\left(32,80 \times 1_{8,108}+\right.$ $\left.\left.43,41 \times 1_{8,156}\right)\right]+(2.850,04 \times 11,13 \times \mathrm{H})$

\section{Restrições da etapa 2}

a. Pressão mínima nos nós;

Assim como executado na etapa 1, a cota piezométrica disponível em cada nó da rede será igual à cota piezométrica de origem, menos as perdas de carga de um percurso da alimentação ao nó considerado.

As equações de restrição serão:

$$
\text { Nó 1: Z - }\left(\mathrm{J}_{1,535}+\mathrm{J}_{1,638}\right) \geq(25+6,0)
$$

Nó 2: Z - $\left(\mathrm{J}_{1,535}+\mathrm{J}_{1,638}+\mathrm{J}_{2,299}+\mathrm{J}_{2,381}\right) \geq(25+5,5)$

Nó 3: $\mathrm{Z}-\left(\mathrm{J}_{1,535}+\mathrm{J}_{1,638}+\mathrm{J}_{2,299}+\mathrm{J}_{2,381}+\mathrm{J}_{3,299}+\mathrm{J}_{3,381}\right) \geq$ $(25+5,5)$

Nó 4: $\mathrm{Z}$ - $\left(\mathrm{J}_{1,535}+\mathrm{J}_{1,638}+\mathrm{J}_{5,381}+\mathrm{J}_{5,432}\right) \geq(25+6,0)$

Nó 5: Z - $\left(\mathrm{J}_{1,535}+\mathrm{J}_{1,638}+\mathrm{J}_{6,299}+\mathrm{J}_{6,381}\right) \geq(25+4,5) \quad$ (40) 
Nó 6: $\mathrm{Z}-\left(\mathrm{J}_{1,535}+\mathrm{J}_{1,638}+\mathrm{J}_{6,299}+\mathrm{J}_{6,381}+\mathrm{J}_{7,204}+\mathrm{J}_{7,252}\right) \geq$ $(25+4,0)$

b. Conservação de energia (Equações 24 e 25);

c. Continuidade nos nós (Equações 26 a 31);

d. Comprimentos dos trechos:

A soma dos comprimentos dos sub-trechos de um trecho deve ser igual ao comprimento do trecho considerado. Sendo o número de trechos igual a 8 , devem ser consideradas oito equações de restrição:

$$
\begin{aligned}
& \text { Trecho } 1: 1_{1,535}+1_{1,638}=2.540 \\
& \text { Trecho } 2: 1_{2,299}+1_{2,381}=1.230 \\
& \text { Trecho 3: } 1_{3,299}+1_{3,381}=1.430 \\
& \text { Trecho 4: } 1_{4,108}+1_{4,156}=1.300 \\
& \text { Trecho 5: } 1_{5,381}+1_{5,432}=1.490 \\
& \text { Trecho 6: } 1_{6,299}+1_{6,381}=1.210 \\
& \text { Trecho 7: } 1_{7,204}+1_{7,252}=1.460 \\
& \text { Trecho 8: } 1_{8,108}+1_{8,156}=1.190
\end{aligned}
$$

e. Não negatividade dos comprimentos:

Todos os comprimentos devem ser maiores ou iguais a zero. Ao todo são 16 sub-trechos, implicando assim em 16 equações de não negatividade para o problema.

$$
1_{1,535} \geq 0 ; 1_{1,638} \geq 0 ; \ldots ; l_{8,156} \geq 0
$$

f. Velocidade máximas e mínimas:

$$
\begin{aligned}
& \mathrm{V}_{1,1} \geq 0,2 \mathrm{~m} / \mathrm{s} ; \mathrm{V}_{1,2} \geq 0,2 \mathrm{~m} / \mathrm{s} ; . \mathrm{V}_{8,2} \geq 0,2 \mathrm{~m} / \mathrm{s} \\
& \mathrm{V}_{1,1} \leq 3,0 \mathrm{~m} / \mathrm{s} ; \mathrm{V}_{1,2} \leq 3,0 \mathrm{~m} / \mathrm{s} ; . \mathrm{V}_{8,2} \leq 3,0 \mathrm{~m} / \mathrm{s}
\end{aligned}
$$

\section{Edição da planilha da etapa 2}

Terminada a elaboração das equações que envolvem o problema, deve-se construir a planilha para proceder à otimização definitiva do Grande Setor.

A planilha vista na Figura 7 apresenta o cálculo hidráulico, as restrições e os custos do sistema de abastecimento (rede mais energia) do Grande Setor, correspondente à solução inicial da etapa 2 do processo de otimização.
Tabela 4. Diâmetros comerciais a serem utilizados na segunda etapa do dimensionamento.

\begin{tabular}{ccc}
\hline Trecho & $\begin{array}{c}\text { Diâmetro } \\
\text { encontrado }(\mathrm{mm})\end{array}$ & $\begin{array}{c}\text { Diâmetros comerciais } \\
\text { internos }(\mathrm{mm})\end{array}$ \\
\hline 1 & 574,0 & 535,0 e 638,0 \\
2 & 359,9 & 299,8 e 381,0 \\
3 & 315,7 & 299,8 e 381,0 \\
4 & 108,4 & 108,4 e 156,4 \\
5 & 384,0 & 381,0 e 432,0 \\
6 & 301,9 & 299,8 e 381,0 \\
7 & 239,0 & 204,2 e 252,0 \\
8 & 108,4 & 108,4 e 156,4 \\
\hline
\end{tabular}

Os significados das colunas da planilha (Figura 7), na parte referente ao cálculo hidráulico, são:

Coluna B: Número do trecho (valores atribuídos de acordo com o projeto).

Coluna C: Vazão no trecho. Valores obtidos na primeira etapa do processo de otimização (variável a ser ainda otimizada). As células \$C\$5:\$C\$6 são idênticas à célula $\$ F \$ 21$, que corresponde à vazão do trecho 1 , obtida na solução otimizada da planilha vista na Figura 6, as células \$C \$7:\$C\$8 são idênticas à célula $\$ F \$ 22$, que corresponde à vazão do trecho 2 obtida na solução otimizada da planilha mostrada na Figura 6, e assim sucessivamente.

Coluna D: Diâmetros a serem utilizados nos trechos (valores extraídos da Tabela 4).

Coluna E: Custo de implantação do tubo, por unidade de comprimento (valores extraídos da Tabela 3).

Coluna F: Comprimentos dos trechos (variável de decisão). Valores inicialmente atribuídos, obedecendo às equações de restrição (42), ...., (49). Nas células \$F\$21:\$F\$28 estão os valores das vazões obtidas na solução otimizada da etapa 1 (ver Figura 6). Na célula $\$ F \$ 29$ se encontra o valor da altura manométrica do bombeamento obtida na solução otimizada da etapa 1 (ver Figura 6), que também será variável de decisão na segunda etapa do PNL2000. A utilização das células, com os valores das vazões idênticos aos valores da coluna $C$, faz parte de um artifício, com o intuito de facilitar a obtenção dos cálculos otimizados, através da ferramenta Solver. Assim, todas as variáveis de decisão vão estar agrupadas em uma única coluna, facilitando a obtenção dos cálculos otimizados através da ferramenta Solver.

Coluna G: Coeficiente de Hazen-Williams (valores atribuídos em função dos diâmetros da coluna D). 


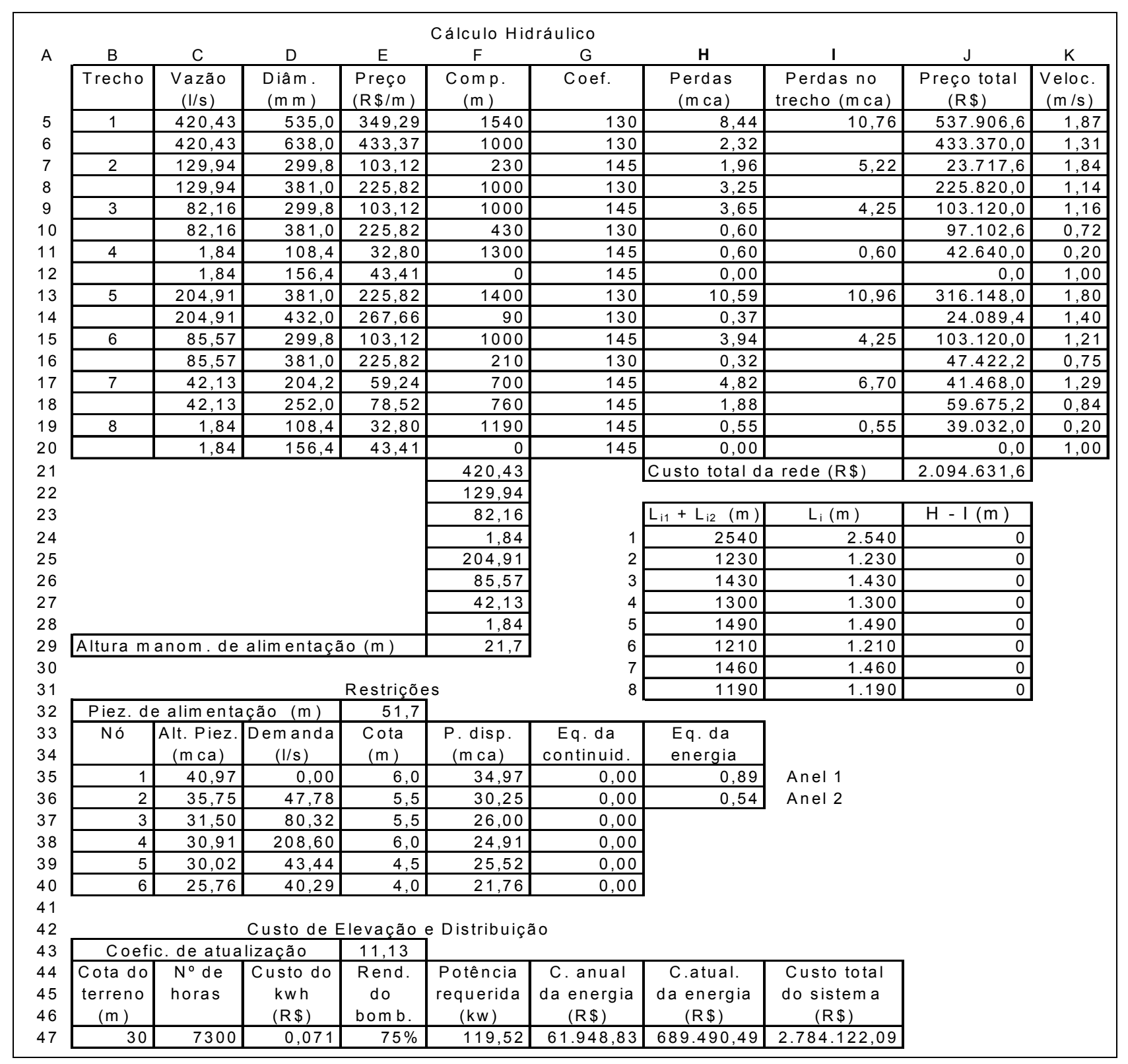

Figura 7. Dimensionamento do Grande Setor - segunda etapa - solução inicial.

Coluna H: Perda de carga no trecho. A célula H5 será:

$=\mathrm{SE}\left(\mathrm{C} 5>=0 ; 10,66^{*}((\mathrm{C} 5 / 1000) / \mathrm{G} 5)^{\wedge} 1,852^{*} \mathrm{~F} 5 /((\mathrm{D}\right.$ $\left.5 / 1000)^{\wedge} 4,87\right) ;-10,66^{*}((-\mathrm{C} 5 / 1000) / \mathrm{G} 5)^{\wedge} 1,852^{\star} \mathrm{F} 5 /(($ $\left.\left.\mathrm{D} 5 / 1000)^{\wedge} 4,87\right)\right)$.

Coluna I: Soma das perdas de carga provocadas por cada segmento de trecho.

Para a célula I5 será: $=\mathrm{H} 5+\mathrm{H} 6$.

Coluna J: Custo total do trecho, que é igual ao custo unitário do tubo utilizado vezes o comprimento do trecho. A célula J5 será: = E5*F5.
Coluna K: Velocidade do trecho. A célula K5 será:

$$
=\mathrm{SE}\left(\mathrm{F} 5>0 ; 1,273^{*}(\mathrm{C} 5 / 1000) /(\mathrm{D} 5 / 1000)^{\wedge} 2 ; 1\right) .
$$

Na parte da planilha referente às restrições foi acrescentado um bloco com três colunas (colunas $\mathrm{H}, \mathrm{I}$ e J) para explicitarem a restrição de comprimento dos sub-trechos (Equações 42, 43, ..., 49). $\mathrm{O}$ significado do bloco de restrições das colunas $\mathrm{H}$, I e J é:

Coluna H: Comprimentos totais dos trechos. 


\begin{tabular}{|c|c|c|c|c|c|c|c|c|c|}
\hline \multirow[b]{2}{*}{ B } & \multirow[b]{2}{*}{$\mathrm{C}$} & \multicolumn{4}{|c|}{ Cálculo Hidráulico } & \multirow[b]{2}{*}{$\mathbf{H}$} & \multirow[b]{2}{*}{$\mathrm{I}$} & \multirow[b]{2}{*}{$\mathrm{J}$} & \multirow[b]{2}{*}{$\mathrm{K}$} \\
\hline & & $\mathrm{D}$ & $\mathrm{E}$ & $\mathrm{F}$ & G & & & & \\
\hline Trecho & $\begin{array}{c}\text { Vazão } \\
(1 / \mathrm{s})\end{array}$ & $\begin{array}{l}\text { Diâm . } \\
(\mathrm{m} \mathrm{m})\end{array}$ & $\begin{array}{l}\text { Preço } \\
(\mathrm{R} \$ / \mathrm{m})\end{array}$ & $\begin{array}{c}\text { Comp. } \\
(\mathrm{m})\end{array}$ & Coef. & $\begin{array}{c}\text { Perdas } \\
\text { (m ca) }\end{array}$ & $\begin{array}{l}\text { Perdas no } \\
\text { trecho ( } \mathrm{m} \mathrm{ca} \text { ) }\end{array}$ & $\begin{array}{c}\text { Preço total } \\
(R \$)\end{array}$ & \begin{tabular}{|l}
$\begin{array}{l}\text { Veloc. } \\
(\mathrm{m} / \mathrm{s})\end{array}$ \\
\end{tabular} \\
\hline \multirow[t]{2}{*}{1} & 420,43 & 535,0 & 349,29 & 0 & 130 & 0,00 & 5,90 & 0,0 & 1,00 \\
\hline & 420,43 & 638,0 & 433,37 & 2540 & 130 & 5,90 & & $1.100 .759,8$ & 1,31 \\
\hline \multirow[t]{2}{*}{2} & 129,95 & 299,8 & 103,12 & 273 & 145 & 2,33 & 5,45 & $28.183,9$ & 1,84 \\
\hline & 129,95 & 381,0 & 225,82 & 957 & 130 & 3,11 & & $216.039,4$ & 1,14 \\
\hline \multirow[t]{2}{*}{3} & 82,17 & 299,8 & 103,12 & 1430 & 145 & 5,22 & 5,22 & $147.461,6$ & 1,16 \\
\hline & 82,17 & 381,0 & 225,82 & 0 & 130 & 0,00 & & 0,0 & 1,00 \\
\hline \multirow[t]{2}{*}{4} & 1,85 & 108,4 & 32,80 & 1300 & 145 & 0,60 & 0,60 & $42.640,0$ & 0,20 \\
\hline & 1,85 & 156,4 & 43,41 & 0 & 145 & 0,00 & & 0,0 & 1,00 \\
\hline \multirow[t]{2}{*}{5} & 204,91 & 381,0 & 225,82 & 1490 & 130 & 11,27 & 11,27 & $336.471,8$ & 1,80 \\
\hline & 204,91 & 432,0 & 267,66 & 0 & 130 & 0,00 & & 0,0 & 1,00 \\
\hline \multirow[t]{2}{*}{6} & 85,58 & 299,8 & 103,12 & 1210 & 145 & 4,77 & 4,77 & $124.775,2$ & 1,21 \\
\hline & 85,58 & 381,0 & 225,82 & 0 & 130 & 0,00 & & 0,0 & 1,00 \\
\hline \multirow[t]{2}{*}{7} & 42,14 & 204,2 & 59,24 & 532 & 145 & 3,66 & 5,95 & $31.507,5$ & 1,29 \\
\hline & 42,14 & 252,0 & 78,52 & 928 & 145 & 2,29 & & $72.877,4$ & 0,84 \\
\hline \multirow[t]{2}{*}{8} & 1,85 & 108,4 & 32,80 & 1190 & 145 & 0,55 & 0,55 & $39.032,0$ & 0,20 \\
\hline & 1,85 & 156,4 & 43,41 & 0 & 145 & 0,00 & & 0,0 & 1,00 \\
\hline \multirow{9}{*}{\multicolumn{4}{|c|}{ Altura man.de cabeceira (m) }} & 420,43 & & \multicolumn{2}{|c|}{ Custo total da rede $(\mathrm{R} \$)$} & $2.139 .748,6$ & \\
\hline & & & & 129,95 & & & & & \\
\hline & & & & 82,17 & & $L_{i 1}+L_{i 2}(m)$ & $\mathrm{L}_{\mathrm{i}}(\mathrm{m})$ & $\mathrm{H}-\mathrm{I}(\mathrm{m})$ & \\
\hline & & & & 1,85 & & \begin{tabular}{r|}
2540 \\
\end{tabular} & 2.540 & 0 & \\
\hline & & & & 204,91 & & 1230 & 1.230 & 0 & \\
\hline & & & & 85,58 & & 1430 & 1.430 & 0 & \\
\hline & & & & 42,14 & & 1300 & 1.300 & 0 & \\
\hline & & & & 1,85 & & 1490 & 1.490 & 0 & \\
\hline & & & & 20,9 & & 1210 & 1.210 & 0 & \\
\hline \multirow{2}{*}{\multicolumn{6}{|c|}{ Restrições }} & 1460 & 1.460 & 0 & \\
\hline & & & & & & 1190 & 1.190 & 0 & \\
\hline \multicolumn{3}{|c|}{ Piezomét. de cabeceira $(\mathrm{m})$} & 50,9 & & & & \multirow{8}{*}{$\begin{array}{l}\text { Anel } 1 \\
\text { Anel } 2\end{array}$} & & \\
\hline Nó & $\begin{array}{c}\text { Alt. Piez. } \\
\text { (m ca) }\end{array}$ & $\begin{array}{c}\text { De m a n da } \\
(\mathrm{I} / \mathrm{s})\end{array}$ & $\begin{array}{l}\text { Cota } \\
(\mathrm{m})\end{array}$ & $\begin{array}{c}\text { P. disp. } \\
\text { (mca) }\end{array}$ & $\begin{array}{c}\text { Eq. da } \\
\text { continuid. }\end{array}$ & $\begin{array}{l}\text { Eq. da } \\
\text { energia }\end{array}$ & & & \\
\hline 1 & 45,03 & 0,00 & 6,0 & 39,03 & 0,00 & 0,00 & & & \\
\hline 2 & 39,59 & 47,78 & 5,5 & 34,09 & 0,00 & 0,00 & & & \\
\hline 3 & 34,36 & 80,32 & 5,5 & 28,86 & 0,00 & & & & \\
\hline 4 & 33,77 & 208,60 & 6,0 & 27,77 & 0,00 & & & & \\
\hline 5 & 33,77 & 43,44 & 4,5 & 29,27 & 0,00 & & & & \\
\hline 6 & 29,00 & 40,29 & 4,0 & 25,00 & 0,00 & & & & \\
\hline \multicolumn{8}{|c|}{ Custo de Elevação e Distribuição } & & \\
\hline \multicolumn{3}{|c|}{ Coeficiente de atualizaçã } & 11,13 & & & & & & \\
\hline \begin{tabular}{|c|} 
Cota do \\
terreno \\
$(\mathrm{m})$
\end{tabular} & \begin{tabular}{|c|}
$N^{\circ}$ de \\
horas
\end{tabular} & $\begin{array}{c}\text { Custo do } \\
\text { kwh } \\
(R \$)\end{array}$ & $\begin{array}{c}\text { Rend. } \\
\text { do } \\
\text { bom b. }\end{array}$ & $\begin{array}{l}\text { Potência } \\
\text { requerida } \\
(\mathrm{kw})\end{array}$ & $\begin{array}{c}\text { C. anual } \\
\text { da energia } \\
(R \$)\end{array}$ & $\begin{array}{c}\text { C.atual. } \\
\text { da energia } \\
(R \$)\end{array}$ & $\begin{array}{c}\text { Custo total } \\
\text { do sistem a } \\
(R \$)\end{array}$ & & \\
\hline 30 & 7300 & 0,071 & $75 \%$ & 115,15 & $59.680,20$ & $664.240,65$ & $2.803 .989,24$ & & \\
\hline
\end{tabular}

Figura 8. Dimensionamento do Grande Setor - segunda etapa - solução definitiva.

A célula H24 será: = F5+F6.

A célula H25 será: = F7+F8.

H31 será: $=$ F19+F20.

Coluna I (\$I $24: \$ \mathrm{I} \$ 31)$ : Valores numéricos dos comprimentos totais dos trechos (valores atribuídos).

Coluna J: Diferenças dos valores das colunas H e I. A célula J24 será: = H24 - I24.

Os cálculos das partes inferiores da planilha correspondentes às restrições e aos custos são iguais aos apresentados na etapa 1 .

\section{Processo de otimização e resultados da etapa 2}

Terminada a elaboração das planilhas, deve-se preencher os parâmetros de entrada da ferramenta Solver do Excel, de maneira semelhante à edição dos dados da parte 1 , e efetuar o processo de otimização, acionando-se "resolver", conforme mostrado na Figura 9.

A planilha da Figura 8 apresenta o resultado definitivo do dimensionamento da rede do Grande Setor, com o sistema de impulsão, realizado 


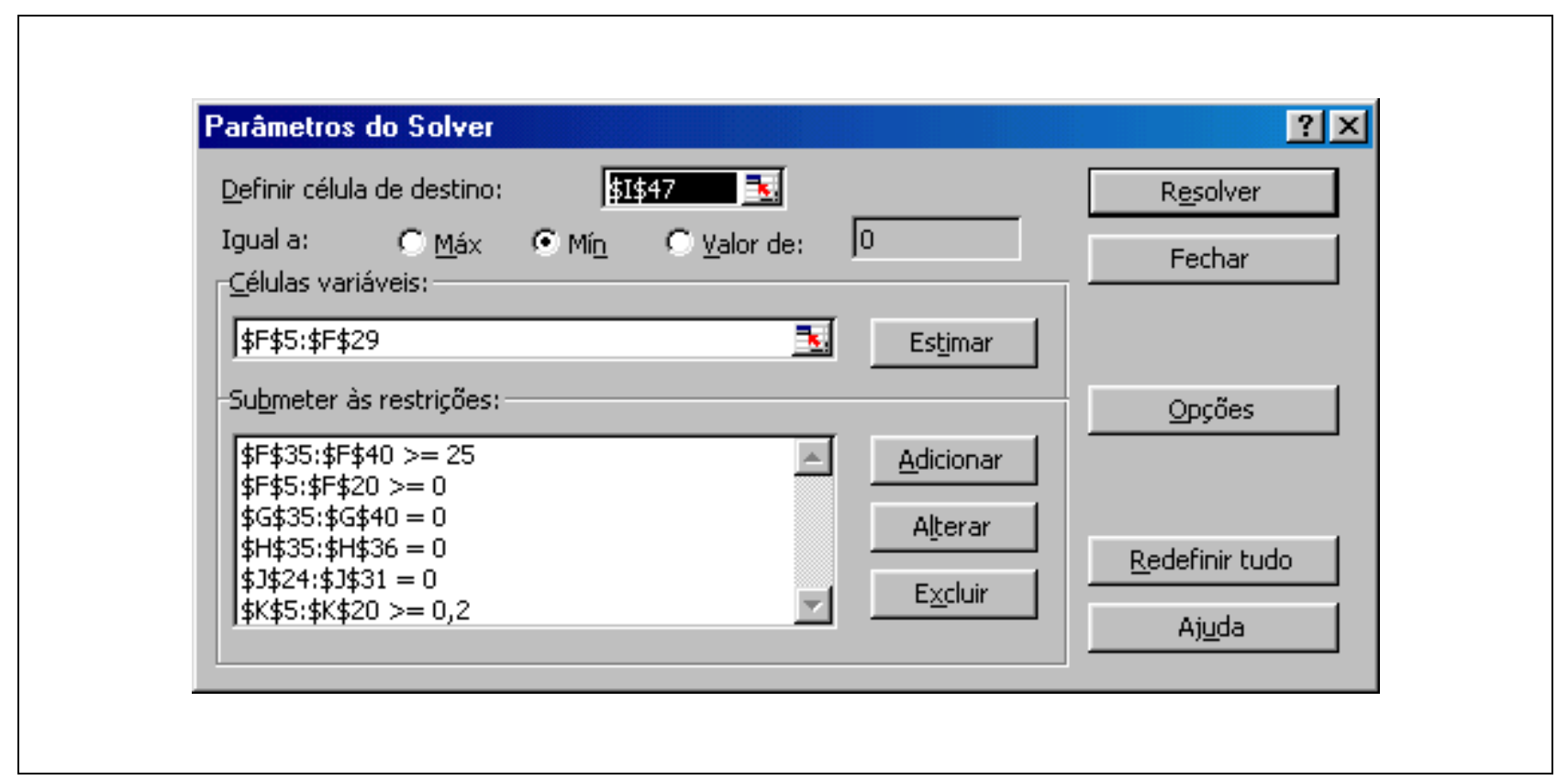

Figura 9. Parâmetros de entrada da ferramenta Solver do Excel para a etapa 2 do dimensionamento do Grande Setor.

pelo PNL2000 (modelo da programação não linear, com a ferramenta Solver). Nela observa-se que o custo mínimo do sistema do Grande Setor (rede mais a energia capitalizada) foi de $\mathrm{R} \$ 2.803 .989,24$, dos quais $\mathrm{R} \$ 2.139 .748,60$ correspondem ao custo de implantação da rede, e R $\$ 664.240,65$ correspondem ao custo energético atualizado. A altura ótima do bombeamento obtida foi de 20,9 metros, que é a dimensão mais adequada, em termos econômicos, para a altura do reservatório elevado do sistema. Nas colunas D e F aparecem, respectivamente, os diâmetros ótimos e os seus comprimentos correspondentes.

A Tabela 5 apresenta os diâmetros ótimos obtidos para o Grande Setor (nominais e internos), para a altura manométrica ótima no sistema de pressurização de 20,9 metros, assim como os comprimentos dos trechos, as vazões e as velocidades médias de circulação da água. Observa-se que o trecho 2 passou a ser composto com tubulações de dois diâmetros distintos consecutivos. O sub-trecho com o diâmetro nominal de $350 \mathrm{~mm}$ terá um comprimento de 957 metros, com origem no nó 1, enquanto que o sub-trecho, a ser ocupado pelo diâmetro nominal de $300 \mathrm{~mm}$, possuirá um comprimento de 273 metros, e terá sua extremidade de jusante conectada ao nó 2. Observa-se também, que o trecho 7 passou a ser igualmente composto com tubulações de dois diâmetros, sendo $928 \mathrm{~m}$ a serem ocupados pelo diâmetro nominal de $250 \mathrm{~mm}$ e 532 metros a serem ocupados pelo diâmetro nominal de $200 \mathrm{~mm}$.
Na planilha vista na Figura 8 estão presentes, ainda, os demais dados referentes ao estado da rede do Grande Setor, para a condição de que a altura manométrica de origem seja igual a 20,9 metros. Pode-se observar, nas células F35:F40, os valores das pressões disponíveis nos nós da rede. Os valores dessas pressões são todos maiores ou iguais a $25 \mathrm{mca}$, como não poderia deixar de ser, já que foi imposta ao modelo a condição de que todas as pressões nos nós teriam que ser maiores ou iguais a 25 mca.

\section{Comparação com o dimensionamento efetuado pela CAGEPA}

A rede, com o depósito elevado de alimentação, apresentada na Figura 2, foi projetada pela Companhia de Água e Esgoto do Estado da Paraíba (CAGEPA), no ano de 1982. Nesse projeto foram utilizados tubos de PVC (diâmetros nominais entre 100 e $300 \mathrm{~mm}$ ) e de ferro dúctil (diâmetros compreendidos entre 350 e $600 \mathrm{~mm}$ ). Os cálculos das perdas de carga contínuas foram realizados mediante o emprego da fórmula de Hazen-Williams, com os coeficientes de rugosidade iguais a 130, para tubos de ferro, e de 145 para tubos de PVC. Para o cálculo do sistema formado pela rede, mais o reservatório, foi utilizado o método clássico de Hardy Cross, cujos resultados definitivos do dimensionamento são apresentados na Tabela 6 . A altura estabelecida do reservatório elevado foi de 24 metros. 
Tabela 5. Diâmetros ótimos do Grande Setor e comprimento dos trechos para a altura manométrica na cabeceira de 18,9 metros.

\begin{tabular}{cccrrc}
\hline Trecho & Diâmetro interno $(\mathrm{mm})$ & Diâmetro nominal $(\mathrm{mm})$ & Comp. $(\mathrm{m})$ & $\mathrm{Q}(\mathrm{l} / \mathrm{s})$ & $\mathrm{V}(\mathrm{m} / \mathrm{s})$ \\
\hline 1 & 638,0 & 600 & 2.540 & 420,43 & 1,31 \\
2 & 381,0 & 350 & 957 & 129,95 & 1,14 \\
& 299,8 & 300 & 273 & & 1,84 \\
3 & 299,8 & 300 & 1.430 & 82,17 & 1,16 \\
4 & 108,4 & 100 & 1.300 & 1,85 & 0,20 \\
5 & 381,0 & 350 & 1.490 & 204,91 & 1,80 \\
6 & 299,8 & 300 & 1.210 & 85,58 & 1,21 \\
7 & 252,0 & 250 & 928 & 42,14 & 0,84 \\
& 204,2 & 200 & 532 & & 1,29 \\
8 & 108,4 & 100 & 1.190 & 1,85 & 0,20 \\
\hline
\end{tabular}

Com base nos diâmetros de cada trecho (Tabela 6), nos comprimentos dos trechos da rede (Tabela 2), nos custos de implantação das tubulações (Tabela 3), e nos dados referentes ao custo da energia e regime de bombeamento, estabelecidos no enunciado do exemplo deste trabalho, os custos totais de investimento da rede e da energia capitalizadas do bombeamento são iguais, respectivamente, a $\mathrm{R} \$ 2.743 .397,10$ e $\mathrm{R} \$ 761.358,25$. O custo total do projeto da CAGEPA (rede mais energia capitalizada) é de $\mathrm{R} \$ 3.504 .755,35$, que é $25 \%$ maior do que o custo total do projeto otimizado calculado mediante a metodologia aqui apresentada.

As pressões disponíveis nos nós da rede dimensionada pela CAGEPA são maiores do que as pressões disponíveis do projeto otimizado. Esse aspecto não compromete o dimensionamento da rede efetuado com o critério de minimização dos custos, já que para essa metodologia foram garantidas as restrições de pressões mínimas em todos os nós da rede (25 mca).

A diferença entre os custos da rede, obtida através da comparação entre o dimensionamento otimizado e não otimizado (Hardy Cross ou Seccionamento fictício), será sempre indefinida. Isso se deve a que o cálculo de redes malhadas através dos métodos convencionais é um problema hidraulicamente indeterminado, não existindo assim uma solução única que possa ser comparada com a solução otimizada de custo mínimo.

\section{CONCLUSÕES}

O modelo PNL2000 proposto mostrou-se eficaz para o dimensionamento otimizado de redes malhadas de distribuição de água. Essa eficácia se
Tabela 6. Vazões e diâmetros nominais da rede dimensionada pela CAGEPA (CAGEPA, 1982).

\begin{tabular}{ccc}
\hline Trecho & Vazão $(1 / \mathrm{s})$ & Diâmetro nominal $(\mathrm{mm})$ \\
\hline 1 & 420,43 & 600 \\
2 & 170,99 & 450 \\
3 & 123,21 & 350 \\
4 & 42,89 & 250 \\
5 & 111,81 & 300 \\
6 & 137,63 & 400 \\
7 & 94,19 & 350 \\
8 & 53,90 & 250 \\
\hline
\end{tabular}

deve à utilização de técnica de programação não linear para o dimensionamento de redes malhadas, que é um problema físico regido por equações que são, na sua grande maioria, não lineares. Além disso, ao se incluir as vazões como variáveis de decisão, procurou-se unir, em um mesmo processo, o balanceamento das vazões nas redes (através das equações de restrição de conservação de massa nos nós e de conservação de energia nos anéis) e a minimização dos custos (que é feita através de modificações dos diâmetros das tubulações e da altura manométrica na origem).

O dimensionamento econômico de redes malhadas através da programação não linear apresenta como vantagens o fato de poder ser implementado através de pacotes computacionais de otimização, onde se incluem as planilhas eletrônicas, que são uma das principais ferramentas da informática utilizadas pelos projetistas; a facilidade que há na sua utilização e compreensão, bem como a possibilidade de modificações na estrutura da função objetivo ou na inclusão de novas restrições, 
o que dá ao PNL2000 maior flexibilidade em se ajustar às várias situações de projeto.

A planilha Excel, através da opção Solver, mostrou ser uma ferramenta potentíssima para a aplicação do modelo PNL2000. Através dela o projetista economiza, de forma significativa, o trabalho de edição das inúmeras equações do modelo, devido à capacidade que a planilha possui de editar, de forma automática, conjuntos de equações, a partir de combinações de células.

A aplicação do PNL2000, através da ferramenta Solver do Excel, permite ao projetista visualizar, em uma única planilha, todo o cálculo hidráulico e econômico de dimensionamento de uma rede malhada, juntamente com o seu sistema de impulsão (seja através de bombeamento ou de reservatório elevado). O PNL2000 permite ao projetista, também, efetuar simulações com respeito a diâmetros de trechos, cotas piezométricas nos nós da rede, incluindo a origem do sistema, demandas de vazões nos nós, etc., e verificar a repercussão hidráulica e econômica de qualquer modificação que possa ocorrer no sistema como um todo.

A ferramenta Solver, no padrão que é apresentado na planilha Excel da Microsoft, está limitada a problemas com um número máximo de, aproximadamente, 200 restrições, o que a torna inviável para o dimensionamento de redes malhadas de médio a grande porte. No entanto, um aumento da capacidade do programa (up grade) da ferramenta Solver, que resolve problemas de grande porte, pode ser adquirido da Microsoft.

\section{REFERÊNCIAS}

ALPEROVITS, E. \& SHAMIR, U. (1977). Design of optimal water distribution systems. Water Resources Research, agosto vol. 13, n6, p. 885 - 900. New York, NY, USA.

CAGEPA - COMPANHIA DE ÁGUA E ESGOTO DO ESTADO DA PARAÍBA (1982). Projeto da rede distribuidora do bairro do Bessa. João Pessoa, PB.

FORMIGA, K. T. (1999). Metodologia de otimização de redes malhadas através da programação não linear. Dissertação de Mestrado. Universidade Federal da Paraíba. Campina Grande, PB.

GESSLER, J. \& WALSKY, T. M. (1985). Technical report EL-85-11: Water distribution system optimization. U.S. Army Corps Engineers, Washington, DC, USA.

GOMES, H. P. (1999). Engenharia de irrigação. Hidráulica dos sistemas pressurizados. $3^{\circ}$ edição. UFPB, Campina Grande.
GOUTER, I. C.; LUSSIER, B. M. \& MORGAN, D. R. (1986). Implications of head loss path choice in optimization of water distribution networks. Water Resources Research, agosto, vol. 22, n5, p. 819 - 822, New York, NY, USA.

GRANADOS, A. (1986). Infraentructuras de regadios - redes colectivas de riego a presión. Servicio de Publicación de E. T. S. I. de Caminos de la Universidad politécnica de Madrid, Espanha.

KARMELI, D.; GADISH, Y. \& MEYERS, S. (1968). Design of optimal water distribution networks. Journal of Pipeline Division, ASCE, vol. 94, n¹0, p. 1 -10. New York, NY, USA.

LASDON, L. S.; WARREN, A. D. \& RATNER, M. S. (1984). GRG2 user's guide. University of Texas at Austin, Austin Tex, USA.

LEAL, A. F. e GOMES, H. P. (1997). Utilização da metodologia Granados para a otimização de redes hidráulicas malhadas. Revista Brasileira de Engenharias Agrícola, vol.1, p.13-16. Campina Grande.

SAVIC, D. A. e WALTERS (1997). Genetic algorithms for least cost of water distribution networks. Jornal of Water ResourcesPlanning ang Management, ASCE, vol. 123, n², p. 67 - 77. New York.

\section{PNL2000 - A Practical Method for Optimal Economic Design of Looped Networks for Water Distribution Systems}

\section{ABSTRACT}

This work presents a practical method for the optimal economic design of looped water distribution systems. The method, here named PNL2000, is to determine the diameter of pipes and pumping piezometric levels, minimizing the total costs (investments and operation) of the water distribution system. The method is based on a non-linear programming technique, implemented with the Solver tool of the Microsoft Excel software. The applicability of the method was demonstrated in the design of a looped network within an urban water distribution system. The results showed that all the hydraulic constraints of the system were satisfied while minimizing the cost.

Keywords: PNL2000; looped networks. 